\title{
La metáfora como estrategia de enseñanza en el aula del siglo XXI
}

\author{
Mónica Pérez Andrada \\ Universidad Nacional de Villa María \\ monicaperezandrada@gmail.com \\ María Mercedes Civarolo \\ Universidad Nacional de Villa María \\ mmciva@hotmail.com
}

Recibido: 01-11-2019 / Aceptado: 02-07-2020

\section{Resumen}

El presente artículo describe el uso, tipo y valoración que los jóvenes de Educación Superior hacen de la metáfora -lingüística y no lingüística- como medio para movilizar y hacer visible su pensamiento, con el propósito de alcanzar mayor profundidad en la comprensión disciplinar. Se ofrecen propuestas didácticas significativas que los educadores configuran incluyendo metáforas y rutinas como recursos para la enseñanza y el aprendizaje. Los resultados preliminares dan cuenta de la necesidad de concebir a este tipo de pensamiento metafórico -divergente y creativo-, como una categoría didáctica para re-pensar y configurar las prácticas educativas del siglo XXI como escenarios de oportunidades para co-aprender y enseñar.

Palabras claves: metáforas cognitivas, comprensión disciplinar, prácticas educativas innovadoras. 


\section{A metáfora como estratégia de ensino na sala de aula do século XXI}

\section{Resumo}

Este artigo descreve o uso, o tipo e as avaliaçóes que os jovens do ensino superior fazem da metáfora - linguística e não linguística - como um meio de mobilizar e tornar visível seu pensamento, a fim de obter maior profundidade no entendimento disciplinar. Propostas significativas de ensino são oferecidas, configuradas pelos educadores, incluindo metáforas e rotinas como recursos para o ensino e a aprendizagem. Os resultados preliminares mostram a necessidade de conceber esse tipo de pensamento metafórico - divergente e criativo - como uma categoria didática para repensar e configurar as práticas educacionais do século XXI como cenários de oportunidades para co-aprender e ensinar.

Palavras chaves: metáforas cognitivas, compreensão disciplinar, práticas educativas inovadoras. 


\title{
Metaphor as a teaching strategy in the 21 st century classroom
}

\begin{abstract}
This article describes the use, type and evaluations that young people of Higher Education make of the metaphor -linguistic and non-linguistic- as a means to mobilize and make their thinking visible, with the purpose of reaching greater depth in disciplinary understanding. Significant teaching proposals are offered that educators configure including metaphors and routines as resources for teaching and learning. The preliminary results show the need to conceive of this type of metaphorical thinking - divergent and creative - as a didactic category to rethink and configure the educational practices of the 21 st century as scenarios of opportunities to co-learn and teach.
\end{abstract}

Keywords: cognitive metaphors, disciplinary understanding, innovative educational practices. 


\section{Introducción}

El presente artículo es un emergente del Proyecto de Investigación ${ }^{1}$ denominado "Pensamiento metafórico y rutinas de pensamiento para la construcción de la comprensión disciplinar y la buena enseñanza en Educación Superior", que se desarrolló en la Universidad Nacional de Villa María, Córdoba, Argentina, durante los años 2018-2019.

El estudio se realizó con una población estudiantil de 180 estudiantes, en dos cátedras universitarias: Teorías del Aprendizaje, y Didáctica General y Currículum, ambas disciplinas corresponden a materias comunes que comparten los profesorados de Lengua Inglesa, Matemática, y Lengua y Literatura y son espacios curriculares de régimen anual (marzo -diciembre).

El problema central de indagación se resume en la pregunta :¿De qué manera el uso de la metáfora, como estrategia de enseñanza o de aprendizaje que forma parte de las configuraciones didácticas, puede contribuir a desarrollar el pensamiento y la comprensión disciplinar?

El trabajo describe uso y valoraciones que los estudiantes hacen de diversos tipos de metáfora durante su formación docente, así como el nivel de calidad de la comprensión disciplinar que alcanzan a partir de algunas propuestas didácticas significativas que se proponen en las cátedras universitarias incluidas en el estudio, para hacer emerger la metáfora como recurso para la enseńanza y el aprendizaje.

Se incluyen diferentes aportes conceptuales a partir de los cuales construimos el marco teórico, para interpretar cómo los estudiantes se expresan en metáforas y de qué manera se pueden adecuar las prácticas educativas en el marco de los procesos de innovación curricular.

El diseño se inscribe en el paradigma cualitativo y corresponde a una metodología de investigación-acción que responde al enfoque de metodología narrativa, de composición hermenéutica e historia documentada en portafolios de trabajo.

1. La fuente de financiamiento del proyecto de investigación estuvo sustentada por la Universidad Nacional de Villa María, y gestionada a través de la Secretaría de Investigación y Extensión del Instituto Académico Pedagógico de Ciencias Humanas. 


\section{Un marco de referencia}

Desde los grandes pensadores griegos, hasta la actualidad, la metáfora ha sido tema de análisis y discusión de poetas, filósofos, psicólogos, lingüistas y críticos literarios a lo largo de la historia de la humanidad y lo continúa siendo. Más allá de su perfil poético- retórico, descubrir la cara menos conocida vinculada al papel cognitivo de las metáforas y su relación con la enseñanza y el aprendizaje, requiere necesariamente lidiar con lo abstracto, con las emociones y pensamientos, además del lenguaje.

En la vida cotidiana continuamente, recurrimos a la metáfora como figura del habla, en donde una palabra o frase, que usualmente designa algo conceptualmente, la aplicamos a otra cosa, es decir, utilizamos el conocimiento acerca de un tipo de cosa para entender o designar otra. Incluso es una habilidad necesaria para adquirir muchas clases de conocimiento. En palabras de Lakoff y Johnson (2015).

"la metáfora es la expresión de una actividad cognitiva conceptual, categorizadora, mediante la cual comprendemos un ámbito de nuestra experiencia en términos de la estructura de otro ámbito de experiencia. La metáfora constituye uno de los mecanismos conceptuales por medio de los cuales representamos el mundo y lo representamos en relativa concordancia con la manera en que lo experimentamos" (p.10).

La búsqueda de antecedentes e investigaciones sobre el vínculo entre metáfora, aprendizaje, enseńanza y aspectos del pensamiento y la experiencia nos lleva a considerar los trabajos de Malaguzzi (2001); Lakokk y Jonhson [1980]2015); Danesi (2004); Gardner (2005); Oliveras (2007); Camilloni, (2014).

Por otra parte, conocer la relación entre la capacidad de producción y expresiones metafóricas de los estudiantes de Educación Superior, en relación con la comprensión disciplinar y su expansión a niveles más profundos, nos remite a las investigaciones sobre la enseñanza comprensiva y el Pensamiento visible (Perkins, 1997,1999, 2014, Pro- 
ject Zero de Harvard), que muestran evidencias de la persistencia de la mente pre-disciplinar y de las dificultades en el pensamiento para alcanzar la comprensión genuina dentro y a través de las disciplinas por parte de los estudiantes; problemática que se conoce como Síndrome del conocimiento frágil y del Pensamiento pobre, que se hace evidente en la imposibilidad de pensar y actuar de manera flexible y creativa con el conocimiento que se posee, trascendiendo las actividades rutinarias y de memorización.

La metáfora como estrategia de enseńanza y aprendizaje surge a partir de pensar cómo transformar la cultura del aula. Perkins (1997) en su libro Un aula para pensar, sostiene que un aula enculturada es aquella en donde se propicia el buen pensamiento, en donde todos los que habitan este espacio, incluso el docente, se esfuerzan por ser imaginativos, reflexivos, inquisidores, en definitiva, por ser buenos pensadores.

Si miramos en retrospectiva, hasta hace unos pocos años, los docentes de nivel superior sosteníamos una particular manera de enseñar basada en el conocimiento objetivo y en saber la disciplina por encima de todas las cosas. El hecho de poseer y dominar un conocimiento formal acerca de algo era suficiente para enseñar con experticia; incluso se creía que por añadidura llevaba implícito el conocimiento didáctico para poder transmitirlo con idoneidad de manera que el alumno pudiera aprenderlo. Actualmente, esta postura que constituye una "teoría ingenua" es ineficiente ante una realidad que es diferente y sumamente compleja. Las aulas universitarias están siendo pobladas por jóvenes que conforman la llamada Generación Z, o los "Net", sujetos que no son estudiantes o trabajadores pasivos, sino que disfrutan siendo protagonistas activos comprometidos con lo que hacen, que manifiestan nuevas maneras de pensar y actuar; portando además conocimientos construidos en muchos casos de manera informal. En este nuevo escenario, la finalidad no puede ser otra que propiciar la formación del pensamiento y la comprensión, lo cual exige estructurar una nueva agenda didáctica (Litwin,1997), con nuevas configuraciones de enseñanza para el nivel superior.

Siguiendo a Malaguzzi (2001); el oficio de educar, la pedagogía, no puede ni debe evitar reflexiones amplias con respecto a los cambios culturales" (p.42), por el contrario, el compromiso de los 
educadores en este cambio cultural es imprescindible e intransferible. Nos corresponde a los profesores pensar la enseñanza de la educación superior desde una nueva mirada, aumentar las posibilidades de los estudiantes de acercarse al conocimiento a través de la resolución de desempeños de comprensión que impliquen diversas y plurales maneras de construir el conocimiento.

La metáfora como estrategia de enseńanza y de aprendizaje es una posibilidad para fomentar el pe nsamiento divergente, tantas veces relegado al olvido en la universidad. Hacer visible este tipo de pensamiento a través de expresiones metafóricas que fomenten la construcción de la comprensión disciplinar es una alternativa novedosa. En este sentido nos planteamos el objetivo general de: analizar de qué manera el pensamiento y las expresiones metafóricas en situaciones de modelización de la enseñanza universitaria, y en procesos de aprendizaje, se vinculan con la construcción de la comprensión disciplinar. Los objetivos específicos que abordaremos son: a) definir configuraciones didácticas y configurar desempeños de comprensión con metáforas, y rutinas de pensamiento que generen oportunidades de hacer visible el pensamiento metafórico y promuevan la comprensión disciplinar; b) describir y caracterizar el tipo de expresiones metafóricas que favorecen la construcción de la comprensión disciplinar; y c) promover la metacognición para hacer visible el pensamiento y facilitar la expansión de la comprensión disciplinar.

\section{Una problemática a ser investigada}

Los frágiles resultados que evidencian las universidades latinoamericanas, en el ámbito de educación intercultural, alfabetización y procesos de comprensión (UNESCO, 2013, p. 28-30), dan cuenta de la necesidad de sentar precedentes científicos sólidos acerca de la enseñanza, a la vez de considerar cuáles son los retos más significativos del Siglo XXI que la sociedad plantea a la educación. Por ello, es imprescindible que la nueva agenda didáctica que estructuremos sea capaz de equilibrar dichas demandas sociales con las nuevas formas de aprender, de pensar y actuar de los jóvenes que habitan las aulas del nivel supe- 
rior. Teniendo en cuenta este aspecto, planteamos nuevos caminos para enseñar y aprender que estimulen el desarrollo de comunidades de pensamiento en las cuales se incluya la metáfora -lingüística y no lingüística- como categoría didáctica, dada su potencialidad para promover la comprensión disciplinar.

\section{Una metodología de investigación-acción}

El presente trabajo responde al paradigma cualitativo de composición hermenéutica e historia documentada, a través de la investigación acción, la cual constituye una opción metodológica de mucha riqueza ya que por una parte permite la expansión del conocimiento y por la otra va dando respuestas concretas a problemáticas que se van planteando los participantes de la investigación, que a su vez se convierten en co-investigadores que participan activamente en todo el proceso investigativo y en cada etapa o eslabón del ciclo que se origina producto de las reflexiones constantes que se propician en dicho proceso (Colmenares y Piñero, 2008, p.105).

El estudio busca indagar sobre la expresión y el tipo de metáforas que utilizan los estudiantes en su proceso de comprensión disciplinar, desde la perspectiva de la transformación de las prácticas educativas al promover la metacognición, hacer visible el pensamiento de los estudiantes y facilitar la expansión de la comprensión disciplinar a través del uso de metáforas, rutinas de pensamiento y diversas formas de realimentación.

Las técnicas de recogida de datos, remiten a la documentación fílmica, fotográfica y registro etnográfico de situaciones de enseñanza y aprendizaje que incluyen metáforas, en la resolución de desempeños de comprensión exploratorios, de investigación guiada y de síntesis, individuales y en comunidades de pensamiento ${ }^{2}$ por parte de los estudian-

2. La expresión comunidades de pensamiento, es un neologismo creado por las autoras del presente artículo en el año 2012, para explicar cómo se trabaja en pequeño grupo (tres o cuatro estudiantes) conformando una comunidad que tiende al pensamiento y a la resolución conjunta de una problemática presentada a nivel áulico. 
tes, que son recopilados en portafolios virtuales de aprendizaje (Google Drive); y el fomento de actividad metacognitiva de los estudiantes para lograr mejores niveles de comprensión. En este sentido, sostenemos a la documentación pedagógica como el arte de recoger y revisitar el conocimiento construido:

La Documentación pedagógica es un proceso de indagación e implica el uso de material recogido como medio para la reflexión e interpretación sistemática y democrática, es llevada a cabo por los educadores en pareja educativa, o en equipo, aunque también implica procesos individuales, y de reflexión colectiva sobre el trabajo realizado (Civarolo y Pérez Andrada, 2019, p.15).

El diseño de investigación se llevó adelante con una muestra de 180 estudiantes, en dos cátedras universitarias anuales: Teorías del Aprendizaje, y Didáctica General y Currículum. Ambas disciplinas corresponden a materias comunes que comparten los profesorados de Lengua Inglesa, Matemática y Lengua y Literatura, en la Universidad Nacional de Villa María, Córdoba, Argentina. El curso Teorías del Aprendizaje se imparte en primer año y el de Didáctica General y Currículum en segundo año, por lo tanto, la población de estudiantes corresponde a cuatro cohortes respectivamente, siendo el promedio etario de 22 años, sin prevalencia de género. El vínculo entre los espacios curriculares y la investigación pudo construirse dado que los tres docentes involucrados cumplimos una doble función de docentes e investigadores, y estamos a cargo de las cátedras antes mencionadas. Además nos acompañan 3 docentes adscriptos, 3 estudiantes becarios, y 2 ayudantes alumnos.

La docencia en forma de investigación, entonces, lleva a la construcción o recreación del conocimiento; tiene su manifestación principal en una visión renovada y crítica del proceso de enseñanza-aprendizaje. Éste, si bien requiere un encuadre institucional, una propuesta plasmada en el currículum y una 
conducción ejercida por el profesor, lo verdaderamente importante es propiciar un espacio en el que el profesor aprenda a la vez que enseñe y el alumno enseñe a la vez que aprenda (Morán Oviedo, 2015; p.20-21).

$\mathrm{Al}$ inicio de cada ciclo lectivo, se informa a los estudiantes de las cátedras antes mencionadas, que nuestra labor en el aula abarca tanto la profesión docente como la práctica investigativa, y que las intenciones pedagógicas, didácticas e investigativas involucran los tópicos, las metas de comprensión, los desempeños y las rutinas de pensamiento como la sistemática retroalimentación con el estudiantado. Se trata de proporcionar modelos ${ }^{3}$ que impliquen la formación del estudiante de educación superior, tanto en la práctica docente como en la investigación, puesto que:

La propuesta de enseñar a investigar con una intención práctica sostiene que es más fecundo y da mejores resultados formar al investigador, configurándolo creativamente y entrenándolo críticamente en la realización concreta e inmediata de las prácticas y procesos que se dan durante la producción de conocimientos científicos (Morán Oviedo, 2015, p.50).

La investigación intenta aportar a la construcción de una teoría didáctica para la Educación Superior y especialmente contribuir a una epistemología práctica de la enseñanza comprensiva, haciendo foco en el diseño de configuraciones didácticas que incluyen metáforas con rutinas de pensamiento.

\section{Metáforas visuales, rutinas y comprensión}

En pleno siglo XXI, los escenarios de actuación profesional en el nivel universitario han cambiado; las investigaciones demuestran que, en las últimas décadas, enseñar se hace cada vez más complejo, las

3. Perkins, D. (1997). Un aula para pensar. Buenos Aires. Aique. "Proporcionar modelos: al planificar la enseńanza (...) se debe pensar en los conocimientos, habilidades, estrategias predisposiciones que invitan a la transferencia (p.207). 
dudas, la falta de certezas, la divergencia son aspectos consustanciales con los que debemos convivir los profesionales de la enseñanza. Por otro lado; el estudiante no pide permiso para aprender y necesita saber casi de manera instantánea si la información a la que está teniendo acceso es significativa. Siguiendo a Burbules (2014), existe una gran diferencia entre:

Lo que llamo el modelo "aprende ahora, usa después", propio de gran parte de la educación tradicional, y lo que podría llamar aprendizaje "en tiempo real" (just in time): acceso a información, conocimiento y habilidades para necesidades particulares en contextos específicos de uso en los que estos recursos son relevantes y útiles en lo inmediato. No imagino que un currículo completo pueda ser mejor aprendido y retenido más efectivamente que cuando se aprende en contextos de uso- usos que tienen valor intrínseco para el aprendiz en un espacio, un tiempo y una circunstancia que significa algo para él (p.132-133).

En este sentido; proponemos que pensar en un aula enculturada (Perkins, 1997) que aporte a la construcción del conocimiento, que movilice el pensamiento y que haga visible el aprendizaje y los modos de aprender implica pensar en estrategias de enseñanza, a partir de la presentación de metáforas visuales y rutinas de pensamiento que permitan a los estudiantes universitarios acercarse a la comprensión disciplinar. La selección de metáforas visuales, o esquemas de imágenes (Johnson, [1987]1991), se realiza con la intención de "dar sentido a la relación entre diversas experiencias" (p. 49), en tanto que la metáfora, involucra a los estudiantes en la exploración, interpretación, y co-aprendizaje.

El éxito de la metáfora [...] depende de la sensibilidad del enunciado al contexto, que es el lugar compartido y colectivo en el que se integra la experiencia y el conocimiento de las cosas. Se diría que unas imágenes funcionan mejor porque se acomodan mejor o concretan mejor con el lenguaje de las cosas mismas (Núñez, 1992:174-175 
El hecho de imbricar metáforas visuales con rutinas de pensamiento emerge de la búsqueda de desarrollo de las capacidades de los estudiantes hacia el buen pensamiento. En las propuestas didácticas se promueven metáforas visuales como provocación y rutinas de pensamiento como acción:

Se puede pensar en las rutinas como procedimientos, procesos o patrones de acción que se utilizan de manera repetitiva para manejar y facilitar el logro de metas o tareas específicas. (...) Para comprender cómo las rutinas de pensamiento se pueden utilizar, y también cómo crear las propias, conviene verlas desde tres perspectivas: como herramientas, como estructuras y como patrones de comportamiento (Ritchhart, Church y Morrison , 2014, p.85-86).

\section{Las metáforas como estrategias de enseñanza}

Las decisiones para llevar adelante los objetivos planteados y las líneas de acción dispuestas se pudieron realizar dado al rol desempeñado. Es decir, en cuanto al proyecto de investigación: "Pensamiento metafórico y rutinas de pensamiento para la construcción de la comprensión disciplinar y la buena enseñanza en Educación Superior", ocupamos el rol de directora y el de integrante respectivamente, y a su vez somos las docentes responsables de las cátedras de Teorías del Aprendizaje y de Didáctica General y Currículum. Esta situación, nos permitió la intervención y construcción de los Programas de estudio, de ambas cátedras, de acuerdo con el Marco de Enseńanza para la Comprensión (MEpC).

Debido a la imposibilidad de poder desarrollar en este escrito todas las actividades que se llevaron adelante durante los dos años que duró la investigación, y a que muchos de los datos recogidos durante el trabajo de campo se encuentran aún en fecundo análisis por su proximidad en el tiempo, circunscribimos este artículo a aquellas situaciones de enseñanza, aprendizaje, y co-aprendizaje con metáforas y rutinas de pensamiento que dan cuenta de la construcción disciplinar por parte del estudiantado. 
Desde la posibilidad que nos ofrece la investigación acción, se presentan dos experiencias suscitadas en la cátedra Teorías del Aprendizaje que corresponde al cursado de primer año de los profesorados de Lengua Inglesa, Matemática, y Lengua y Literatura. La primera situación que se describe recupera la presentación de la cátedra a los estudiantes ingresantes, a quienes se explica el programa de estudio y haciendo mención al MEpC, e informando a los estudiantes la doble función como docentes e investigadores del equipo de cátedra, de los adscriptos, becarios, y ayudantes alumnos que nos acompañan, invitándolos a ellos también como partícipes necesarios de la investigación.

La segunda experiencia tiene especial relación con el bloque tres del mencionado programa, el que busca abordar la inteligencia específicamente desde el interrogante: qué implica ser inteligente en el siglo XXI.

La docencia en forma de investigación, entonces, lleva a la construcción o recreación del conocimiento; tiene su manifestación principal en una visión renovada y crítica del proceso de enseńanza-aprendizaje. Éste, si bien requiere un encuadre institucional, una propuesta plasmada en el currículum y una conducción ejercida por el profesor, lo verdaderamente importante es propiciar un espacio en el que el profesor aprenda a la vez que enseñe y el alumno enseñe a la vez que aprenda (Morán Oviedo, 2015; p.20-21).

\section{El aprendizaje como metáfora}

La clase inicia con la presentación del programa de la cátedra Teorías del Aprendizaje a los estudiantes ingresantes a primer año, de los tres profesorados mencionados precedentemente. Se informa a los estudiantes que el mismo está diseñado de acuerdo al MEpC; mientras que, en la pantalla del salón de clase, se proyecta una imagen del "Barco de mariposas" perteneciente al pintor surrealista Vladimir Kush.

La propuesta áulica conlleva presentar la imagen de Kush como un disruptivo visual y perceptivo, la propuesta visual se acompaña con 
la rutina de pensamiento: ver - pensar - preguntarse; y con las preguntas orientadoras: Si el aprendizaje fuera una metáfora, ¿cuál sería?, ¿por qué?

Ilustración 1 Barco de mariposas; perteneciente al artista Vladimir Kush

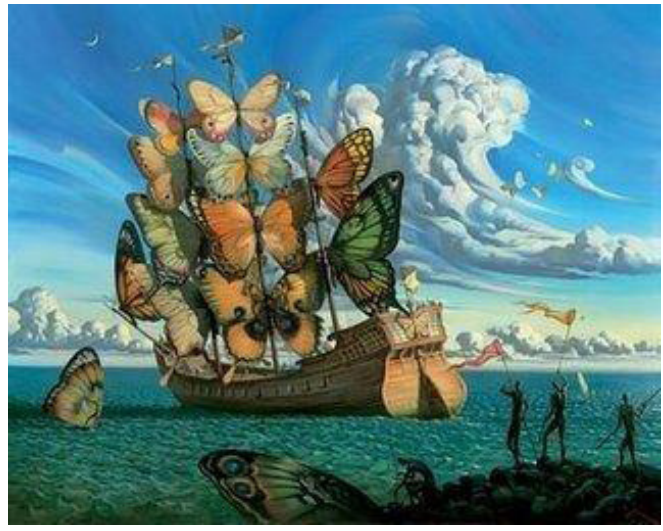

La metáfora visual propone una dualidad muy significativa, sobre lo que significa "ver", cuando nos acercarnos al objeto de conocimiento, Oliveras (2007):

¿Qué hace posible el ver metafórico, es decir, el ver una cosa en otra? Es preciso hacer aquí una aclaración terminológica. No siempre cuando usemos la palabra "ver" atenderemos al sentido literal del término, que es aquel que corresponde a la metáfora visual. Cuando hablemos de metáfora en general, ver tendrá también un sentido metafórico, en tanto la imagen metafórica verbal no se presenta a la visión sino a la imaginación (p.20).

La metáfora visual permite ver lo que el alumno ya conoce, en tanto le lleva a indagar en sus conocimientos a priori, siendo también posible acercarse a la interpretación que realiza sobre el objeto visualizado, y a cómo, a través de su imaginación, puede relacionar o encontrar semejanzas entre objetos desconocidos. Así, entendemos, que "las metáforas, no navegan sólo en un mar de palabras. Orientan la comprensión y construcción de significados y sustentan la construcción del conocimiento e influyen significativamente sobre ésta” (Camilloni, 2014, p. 20). 
A continuación (página siguiente), presentamos la documentación realizada a partir de los desempeños de comprensión ${ }^{4}$ propuestos con sus metáforas y rutinas. En la primera fila se describe la rutina, propósito y contenido; en la segunda fila, se visibilizan el tipo de metáforas que emergieron de las expresiones de los estudiantes, mientras la tercera fila da cuenta de algunas de las expresiones metafóricas surgidas en este primer desempeño exploratorio de la clase 1.

Tabla 1. ¿Si el aprendizaje fuera una metáfora cuál sería?, ¿Por qué?

\begin{tabular}{|c|c|c|c|}
\hline Rutina & Descripción & Propósito & Contenidos \\
\hline $\begin{array}{l}\text { Ver- pcnsar - } \\
\text { preguntarse }\end{array}$ & $\begin{array}{l}\text { Desarrollo } \\
\text { de ideas, } \\
\text { interpretación, } \\
\text { construcción de } \\
\text { teorias basadas en } \\
\text { evidencias y } \\
\text { curiosidad. }\end{array}$ & $\begin{array}{l}\text { Enfatizar cn } \\
\text { la importancia de la } \\
\text { observación. } \\
\text { Estimular la } \\
\text { curiosidad y la } \\
\text { reflexión. }\end{array}$ & $\begin{array}{l}\text { Imagen/objcto como } \\
\text { estimulo que provoca el } \\
\text { pensamiento. } \\
\text { El objeto es desconocido } \\
\text { para los estudiantes, permite } \\
\text { diferentes niveles de análisis } \\
\text { e interpretaciones, desde } \\
\text { distintas perspectivas. }\end{array}$ \\
\hline Metáforas & \multicolumn{3}{|c|}{$\begin{array}{l}\text {-Metáfora sinestésica: describe la confusión de sensaciones } \\
\text { percibidas por los sentidos corporales. } \\
\text {-Metáforas objetuales: combina elementos de uso cotidiano, } \\
\text { nuevos, desechados, ecológicos, fuera de su contexto habitual y expuestos } \\
\text { de manera que cambian su significado inicial (utilitario) y se convierten } \\
\text { en obras de arte. }\end{array}$} \\
\hline $\begin{array}{l}\text { Expresiones } \\
\text { metafóricas } \\
\text { recogidas a } \\
\text { través de la } \\
\text { documentación }\end{array}$ & \multicolumn{3}{|c|}{$\begin{array}{l}\text { "El aprendizaje es un parche en la vela de un barco, ayuda a } \\
\text { reparar la vela de la ignorancia que nos impulsa por el mar del saber". } \\
\text { "El aprendizaje es el recorrido de un ciclista por un camino } \\
\text { mixto, un camino que contempla tramos lisos y fáciles de recorrer, otros } \\
\text { un poco más sinuosos y otros empinados con fallas, piedras y golpes" }\end{array}$} \\
\hline
\end{tabular}

Fuente: elaboración propia.

4. Pogré y Lombardi (2003) definen a los desempeños de comprensión como actividades que demandan de los estudiantes el empleo del conocimiento en formas y situaciones nuevas. Los mismos permiten a los alumnos reconfigurar, expandir y construir saberes a partir de los conocimientos previos. Los desempeńos permiten a la vez construir y evidenciar comprensión. De acuerdo a la etapa de desarrollo del tópico generativo, se recurre al trabajo con desempeños de exploración, de investigación guiada o de síntesis. 


\section{La inteligencia en el siglo XXI}

En el Bloque 3 del programa de estudio, de la cátedra Teorías del Aprendizaje, se aborda el tópico "Inteligencia", cuya denominación es; “¿Todos somos inteligentes? ¿Podemos volvernos más inteligentes? En esta oportunidad se recuperan dos experiencias pertenecientes a este bloque de contenidos, el primero que explicaremos atiende al concepto de inteligencia, la evolución del término, y su relación con ideas preconcebidas; y la segunda experiencia contempla la teoría de las inteligencias múltiples desarrollada por Howard Gardner (1995).

Propuesta áulica: se invita a los estudiantes que se reúnan en comunidades de pensamiento e interactúen con fotografías de personas consideradas mentes brillantes, la actividad se acompaña con la rutina: creo-me problematizo-exploro, y se solicita que elaboren un texto utilizando una metáfora, en donde se explique y argumente qué es la inteligencia, qué significa ser inteligente hoy, y qué preguntas les genera el tema.

El contenido: Inteligencia, presentado con fotografías de mentes extraordinarias, busca distinguir dos momentos sustanciales en la toma de decisión del estudiante: uno que tiene que ver con lo percibido y otro con lo concebido, puesto que, la imagen inicialmente devela al personaje - lo percibido-, pero también representa, aquello que la imagen del personaje, transmite para el ámbito y cultura en donde destacó -lo concebido-, y que por su característica se ha vuelto en una imagen universal.

En la metáfora visual, el nivel de lo percibido, correspondiente a la identificación, es el del primer impacto, el de la sorpresa. Luego, en un segundo momento, el receptor pasa del plano de lo impropio (percibido) al de lo propio concebido (Oliveras, 2007, p.41).

La metáfora, desde esta propuesta, es una invitación conceptual, una especie de juego de imaginación que requiere la movilización del pensamiento de los estudiantes, en tanto, desde sus concep- 
ciones previas o sus esquemas anticipatorios ${ }^{5}$ intentarán mediante un esfuerzo metacognitivo determinar si todas las fotografías representan a mentes extraordinarias. En su argumentación se pondrá de manifiesto un debate entre lo percibido y lo concebido y, a su vez, se determinará si cada uno de los personajes puede considerarse "inteligente", de acuerdo al contexto cultural y ámbito de actuación en el que se ha desempeñado. Igualmente, a solicitarles que elaboren una metáfora que implique reconstruir el concepto de inteligencia a partir de considerar las fotografías, visibiliza que "La metáfora, no ilustra, no representa ni traduce un contenido preexistente; por el contrario, lo crea" (Oliveras, 2007, p.71).

A continuación, se presentan los interrogantes, las fotografías, la rutina creo-me problematizo-exploro. El cuadro de doble entrada explica, en la primera fila, la definición de la rutina propósito y contenidos; en la segunda fila, el tipo de metáforas que emergieron y, finalmente, en la tercera fila se consignan las expresiones metafóricas enunciadas por los estudiantes.

Ilustración 2. Inteligencia: mentes extraordinarias y metáforas
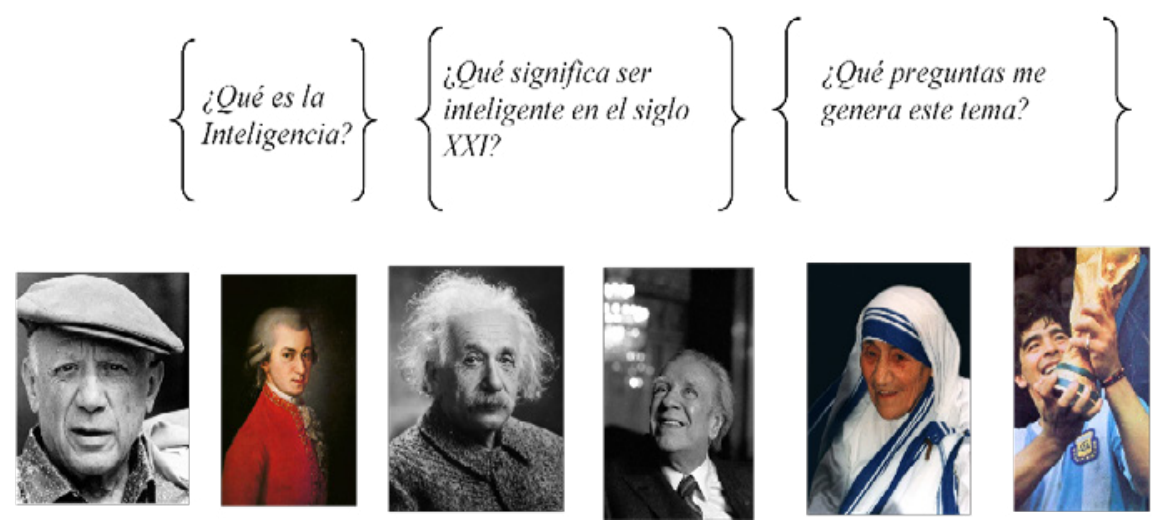

5. Los esquemas anticipatorios; son un concepto desarrollado por Ulric Neisser (1976), para explicar que la actividad de quien percibe un objeto, está dirigida por el esquema preexistente, y es fundamentalmente: acción, construcción y actividad cíclica, estrechamente ligada a la situación de estímulo. 
Tabla 2. ¿Qué significa ser inteligente en el siglo XXI?

\begin{tabular}{|c|c|c|c|}
\hline Rutina & Descripción & Propósito & Contenidos \\
\hline $\begin{array}{l}\text { Creo- me } \\
\text { problematizo- } \\
\text { exploro }\end{array}$ & 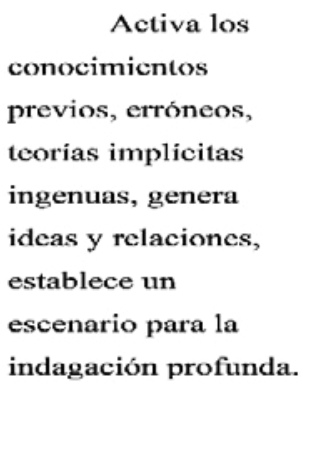 & $\begin{array}{l}\text { Promueve } \\
\text { un pensamiento de } \\
\text { indagación. }\end{array}$ & $\begin{array}{l}\text { Es una estrategia } \\
\text { para introducir un tópico, } \\
\text { tema o concepto. Ayuda a } \\
\text { los estudiantes a tomar } \\
\text { conciencia de lo que } \\
\text { saben y a } \\
\text { problematizarse. Los } \\
\text { docentes adquieren un } \\
\text { conocimiento sobre el } \\
\text { nivel conceptual de los } \\
\text { estudiantes. }\end{array}$ \\
\hline Metáforas & \multicolumn{3}{|c|}{$\begin{array}{l}\text {-Metáforas conceptuales. I a metáfora conceptual es un } \\
\text { fenómeno de cognición en el que un área semántica o dominio se } \\
\text { representa conceptualmente en términos de otro. } \\
\text {-Metáloras espaciales: los gestos metafóricos espontáncos } \\
\text { presentan un mapeo corporal. }\end{array}$} \\
\hline $\begin{array}{l}\text { Expresiones } \\
\text { metafóricas } \\
\text { recogidas a } \\
\text { través de la } \\
\text { documentación }\end{array}$ & \multicolumn{3}{|c|}{$\begin{array}{l}\text { "La inteligencia es el mar, podés ver un comienzo pero no un } \\
\text { final". } \\
\text { "La inteligencia es un músculo, parque mientras más lo } \\
\text { ejercitas, mejor uso harás de él". } \\
\text { "La inteligencia es una computadora porque necesita estar } \\
\text { prendida y saber usarla para obtener resultados" }\end{array}$} \\
\hline
\end{tabular}

\section{Metáforas e inteligencias múltiples}

En esta ocasión, se presenta a los estudiantes diversas fotografías de esculturas ${ }^{6}$, vinculadas a cada una de las inteligencias múltiples desarrolladas por el psicólogo e investigador Howard Gardner de la Universidad de Harvard. Las imágenes representan a los ocho tipos de inteligencias que desarrolló Gardner (1995): Inteligencia musical, inteligencia lógico matemática, inteligencia lingüística; inteligencia naturalista; inteligencia visual-espacial; inteligencia cinético-corporal; y las inteligencias personales: inteligencia interpersonal; e inteligencia intrapersonal.

6. Ver Blog Howard Gardner http://multipleintelligencesoasis.org/about/thecomponents-of-mi/\#box-6 
La propuesta se inicia, solicitando a los estudiantes que observen detenidamente cada una de las imágenes y que intenten encontrar algún tipo de relación con el tópico Inteligencia. Mediante la rutina ¿Qué te hace pensar eso?, se anima a los estudiantes a expresarse mediante la oralidad, utilizando su cuerpo, buscando o escribiendo un poema, o la representación simbólica que ellos prefieran, puesto que "la esencia de la metáfora es entender y experimentar un tipo de cosa en términos de otra" (Lakoff y Johnson 2015, p.41). Este tipo de actividad difiere de la anterior, dado que en las esculturas "desaparece la percepción, para que surja la imaginación” (Oliveras, 2007, p.135). Parafraseando a Johnson (2004), plantear actividades a través de esquemas de imágenes, ayuda a entender la corporeidad del pensamiento, los esquemas de imágenes son una fuente de metáforas, que se originan en nuestras sensaciones corporales como el movimiento, la manipulación de objetos, relacionados con nuestra experiencia física.

La metáfora revela, que las estructuras empleadas para operar una síntesis de nuestros sistemas conceptuales, provienen de nuestra experiencia corpórea (...) La metáfora, revela, además, que el pensamiento es imaginativo, en el sentido que los conceptos, que no están basados directamente en la experiencia, emplean la metáfora, o sea la figuración mental. Es esta capacidad imaginativa la que permite el pensamiento abstracto y lleva a la mente más allá de lo que podemos ver y sentir, según Lakoff y Johnson (citados por Danesi, 2000, p.110-111).

A continuación, se comparten las imágenes de las esculturas que representan a las inteligencias múltiples, y un cuadro de doble entrada que explica: en la primera fila la definición de la rutina propósito y contenidos, en la segunda fila el tipo de metáforas que emergieron, y en la tercera fila las expresiones metafóricas enunciadas por los estudiantes. 
Ilustración 3. Imágenes de esculturas que representan a las ocho inteligencias múltiples
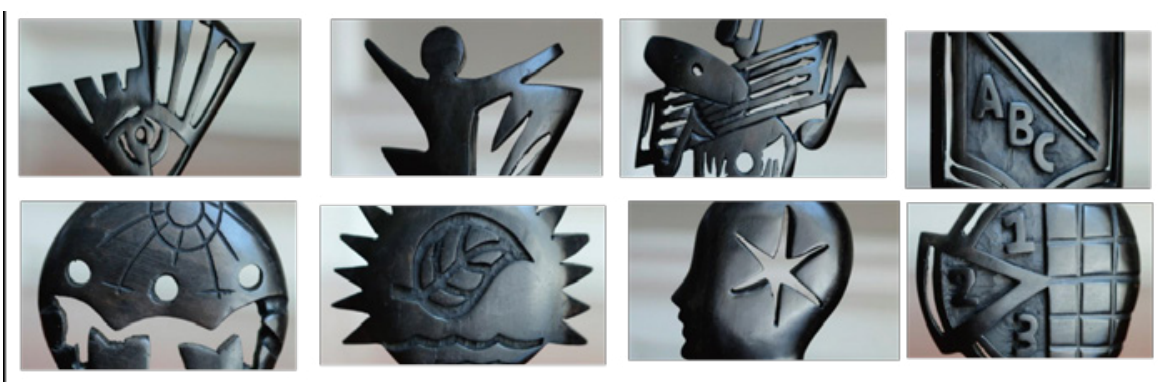

Tabla 3. Metáforas, experiencias e inteligencias múltiples

\begin{tabular}{|c|c|c|c|}
\hline Rutina & Descripción & Propósito & Contenidos \\
\hline $\begin{array}{l}\text { ¿Qué te hace } \\
\text { pensar eso? }\end{array}$ & $\begin{array}{l}\quad \text { Estrategia para } \\
\text { construir explicaciones. } \\
\text { Iniciar la } \\
\text { argumentación. } \\
\text { Promueve el } \\
\text { razonamiento basado en } \\
\text { la evidencia. }\end{array}$ & $\begin{array}{l}\text { Interpretación con } \\
\text { justificación }\end{array}$ & $\begin{array}{l}\text { Los interrogantes } \\
\text { pueden variar; ¿Qué } \\
\text { observaste que te hizo } \\
\text { decir eso?, ¿en qué basas } \\
\text { tu opinión o } \\
\text { interpretación?, ¿qué } \\
\text { sabes o conoces sobre el } \\
\text { tema? }\end{array}$ \\
\hline Metáforas & \multicolumn{3}{|c|}{$\begin{array}{l}\text {-Metáforas conceptuales del tipo asociativas, no son sólo } \\
\text { expresiones verbales. Se relacionan con modos de pensar y pueden llegar } \\
\text { a asumir una función heuristica.1. La metáfora revela, por demás, que el } \\
\text { pensamiento es imaginativo, en el sentido de que los conceptos que no } \\
\text { están directamente basados en la experiencia implican la metáfora, o sea } \\
\text { la figuración mental } \\
\text { - Los entes geométricos pertenecen al género de metáforas que } \\
\text { pueden ser representadas visualmente, ser descritas con diversos niveles } \\
\text { de generalidad, y que permiten ser operadas con carácter explicativo } \\
\text { causal. }\end{array}$} \\
\hline $\begin{array}{l}\text { Expresiones } \\
\text { metafóricas } \\
\text { recogidas a } \\
\text { través de la } \\
\text { documentación }\end{array}$ & \multicolumn{3}{|c|}{$\begin{array}{l}\text { "La inteligencia es la combinación de ciertos ingredientes, para } \\
\text { alcanzar un plato exquisito". } \\
\text { "Las inteligencias son elementos interrelacionados, al igual que } \\
\text { un ecosistema, la flora y fauna se complementan". }\end{array}$} \\
\hline
\end{tabular}




\section{Algunas conclusiones provisionales}

Las condiciones y retos que se nos plantean a los educadores universitarios, frente a la nueva cultura de aprendizaje que sostienen los jóvenes que habitan actualmente nuestras aulas, nos llevó a plantearnos a la metáfora como estrategia de enseñanza en el aula del siglo $X X I$, y como estrategias de aprendizaje del estudiante, en tanto la metáfora como expresión y apropiación del conocimiento es un tropo que ayuda a los estudiantes a desarrollar el pensamiento y la comprensión disciplinar.

La propuesta consistió en el diseño de configuraciones de clases específicas y desempeños de comprensión con rutinas de pensamiento y metáforas tanto lingüísticas como no lingüísticas que fueron documentadas con diferentes tipos de registros; los trabajos de los estudiantes fueron recogidos en portafolios de aprendizaje, con registros fotográfico, en diarios de campo, entrevistas y grupos focales. La documentación pedagógica narrativa realizada por el equipo de cátedra, permite rescatar y caracterizar el uso legítimo que los estudiantes realizan de expresiones metafóricas para organizar su pensamiento y tomar decisiones para promoverlo.

Es posible inferir asimismo que las configuraciones didácticas que más favorecen procesos de desarrollo del pensamiento y la comprensión están vinculadas con propuestas didácticas integrales, con clases que proponen diferentes puertas de entrada al conocimiento -estéticas, experienciales, narrativas, lógicas cuantitativas, entre otras-, respetando la diversidad en el aula y los procesos de aprendizaje de cada estudiante, en las que hay una cultura fuerte de pensamiento porque se enseña a pensar fundadamente.

En el marco de accesos estéticos, las metáforas visuales en la explicación didáctica del profesor tienen mucha fuerza para generar lo que se denomina engagement de los estudiantes, es decir una motivación intrínseca para activar conocimientos previos y experiencias relevantes que invitan a participar, a debatir. La dupla metáfora + rutina de pensamiento invita a pensar con otros, a resolver una consigna creativa que constituye una provocación y se vincula con el contenido disciplinar. 
Las metáforas lingüísticas y no lingüísticas son concebidas por los estudiantes como estrategias de aprendizaje de gran potencialidad para construir comprensión; les exigen participación activa desde el pensamiento, requieren asumir desafíos cognitivos, desaprender viejas rutinas y monitorear desde un esfuerzo metacognitivo sus procesos de aprendizaje. El apoyo del docente, desde el modelaje y la realimentación constante en sus múltiples formas, crea un círculo virtuoso, mientras que la resolución de desempeños de comprensión en comunidades de pensamiento permite hacer visible el pensamiento de los estudiantes, a través de expresiones metafóricas cuando construyen comprensión disciplinar de manera cooperativa.

Con respecto a la relación que existe entre las estrategias de enseñanza y de aprendizaje que establecen los profesores con los niveles de comprensión disciplinar que alcanzan los estudiantes, una configuración que constituye un escenario diverso y rico en puertas de entrada permite conciliar ambas estrategias como complementarlas, ya que no se puede pensar una separada de la otra. Enseñar con metáforas modela el pensamiento y las expresiones metafóricas y lleva a pensar y resolver desempeños valiéndose de ese tipo de pensamiento con procesos metacognitivos.

El uso y tipo de metáforas que se evidencian con mayor sistematicidad en las expresiones de los estudiantes, ante las diferentes propuestas áulicas, refieren a metáforas cognitivas, orientacionales y estructurales (Lakoff y Johnson, [1980], 2015); metáforas conceptuales (Camilloni, 2014) y metáforas corporales (Johnson, 2004; Danesi, 2004).

Estas conclusiones provisionales aportan a la construcción, desde el punto de vista didáctico, de una teoría de la enseñanza comprensiva en la educación superior y a una epistemología práctica, justificada por evidencias empíricas que resaltan la importancia de promover la enculturación (Perkins, 1997) del aula universitaria como enfoque general que apuesta al desarrollo de competencias de pensamiento que trascienden el pensamiento lógico e introducen el divergente, así como el de competencias comunicacionales que se corporizan en diferentes lenguajes y permiten construir comprensión desde puertas de entrada no convencionales y atractivas. 


\section{Bibliografía}

Burbules, N. (2014). El aprendizaje ubicuo: Nuevos Contextos, Nuevos Procesos. Revista Entramados - Educación Y Sociedad. Illinois. Año 1 Número 1- 2014

Camilloni, A. (2014). Las metáforas conceptuales en la construcción del discurso pedagógico. Revista de Educación. Año 5 No7,2014. p 17 -32.

Civarolo, M.M. y Pérez Andrada, M. (2019). Primeros pasos en la Documentación pedagógica. Cómo hacer visible la cultura de la infancia. Buenos Aires. Hola Chicos.

Colmenares, A.M y Piñero, M.L (2008). La investigación acción. Una herramienta metodológica heurística para la comprensión y transformación de realidades y prácticas socio-educativas. Caracas. Laurus. Revista de Educación, Año 14, Número 27, p.95-114.

Danesi, M. (2004). Metáfora, pensamiento y lenguaje (una perspectiva viquiana de teorización sobre la metáfora como elemento de interconexión). Traducción Sevilla Fernández, J. Toronto. Colección Mínima del CIV.

Danesi, M. (2000). Sentido, concepto y metáfora en Vico: Una óptica interpretativa de las investigaciones científicas sobre la metáfora. Cuadernos sobre Vico. Sevilla. 11-12; 1999-2000.

Gardner, H. (2014). Inteligencias múltiples. La teoría en la práctica. Barcelona. Paidós.

Gardner, H. (2005). Arte, Mente y Cerebro. Una aproximación cognitiva a la creatividad. Buenos aires. Paidós Ibérica.

Gardner, H. (1995). Inteligencias Múltiples. La Teoría en la Práctica. Barcelona. Paidós

Johnson, M. ([1987]1991). El cuerpo en la mente. Fundamentos corporales del significado, la imaginación y la razón. Madrid. Editorial Debate S.A.

Lakokk, G. y Johnson, M. ([1980]2015). Metáforas de la vida cotidiana. Buenos Aires. Cátedra Teorema.

Litwin, E. (2008). El oficio de enseñar. Buenos Aires. Paidós. 
Litwin, E. (1997). Las configuraciones didácticas. Una nueva agenda para la enseñanza superior. Buenos Aires. Paidós.

Malaguzzi, L. (2001). La Educación infantil en Reggio Emilia. Temas de infancia. Barcelona. Rosa Sensat - Octaedro.

Morán Oviedo, P. (comp.). (2015). Docencia e investigación en el aula. Una relación imprescindible. México. IISUE. Universidad Nacional Autónoma de México.

Núñez, R. (1992). La poesía. Madrid. Síntesis.

Oliveras, E. (2007). La metáfora en el arte. Retórica y filosofía de la imagen. Buenos Aires. Emecé Editores.

Perkins, D. et. al. (1997). Un Aula para pensar, aprender y enseñar en una cultura de pensamiento. Buenos Aires. Aique.

Ritchhart, R, Church, M. \& Morrison, K. (2014). Hacer visible el pensamiento. Cómo promover el compromiso, la comprensión y la Autonomía de los estudiantes. Buenos Aires. Paidós.

UNESCO. (2013). Situación Educativa de América Latina y el Caribe: Hacia la educación de calidad para todos al 2015. Santiago. Chile. Salesianos Impresores S.A. Recuperado de: http://www. unesco.org/new/fileadmin/MULTIMEDIA/FIELD/Santiago/ images/SITIED-espanol.pdf 